\title{
P2Y1 agonist HIC in combination with androgen receptor inhibitor abiraterone acetate impairs cell growth of prostate cancer
}

\author{
Hien Thi Thu Le ${ }^{1} \cdot$ Akshaya Murugesan $^{1,2} \cdot$ Nuno R. Candeias $^{3,4} \cdot$ Thiyagarajan Ramesh $^{5}$. Olli Yli-Harja ${ }^{6,7}$. \\ Meenakshisundaram Kandhavelu ${ }^{1}$ (i)
}

Accepted: 24 January 2022 / Published online: 7 February 2022

(c) The Author(s) 2022

\begin{abstract}
$\mathrm{P} 2 \mathrm{Y}$ receptors belong to the large superfamily of G-protein-coupled receptors and play a crucial role in cell death and survival. P2Y1 receptor has been identified as a marker for prostate cancer (PCa). A previously unveiled selective P2Y1 receptor agonist, the indoline-derived HIC (1-(1-((2-hydroxy-5-nitrophenyl)(4-hydroxyphenyl)methyl)indoline-4-carbonitrile), induces a series of molecular and biological responses in PCa cells PC3 and DU145, but minimal toxicity to normal cells. Here, we evaluated the combinatorial effect of HIC with abiraterone acetate (AA) targeted on androgen receptor (AR) on the inhibition of PCa cells. Here, the presence of HIC and AA significantly inhibited cell proliferation of PC3 and DU145 cells with time-dependent manner as a synerfistic combination. Moreover, it was also shown that the anticancer and antimetastasis effects of the combinratorial drugs were noticed through a decrease in colony-forming ability, cell migration, and cell invasion. In addition, the HIC + AA induced apoptotic population of PCa cells as well as cell cycle arrest in G1 progression phase. In summary, these studies show that the combination of P2Y1 receptor agonist, HIC and AR inhibitor, AA, effectively improved the antitumor activity of each drug. Thus, the combinatorial model of HIC and AA should be a novel and promising therapeutic strategy for treating prostate cancer.
\end{abstract}

Keywords Prostate cancer $\cdot$ Abiraterone acetate $\cdot$ Indoline $\cdot$ Apoptosis $\cdot$ Proliferation

Meenakshisundaram Kandhavelu

Meenakshisundaram.kandhavelu@tuni.fi

1 Molecular Signaling Group, Faculty of Medicine and Health Technology, Tampere University and BioMediTech,

P.O.Box 553, 33101 Tampere, Finland

2 Department of Biotechnology, Lady Doak College, Thallakulam, Madurai 625002, India

3 Faculty of Engineering and Natural Sciences, Tampere University, Korkeakoulunkatu 8, 33101 Tampere, Finland

4 LAQV-REQUIMTE, Department of Chemistry, University of Aveiro, 3810-193 Aveiro, Portugal

5 Department of Basic Medical Sciences, College of Medicine, Prince Sattam Bin Abdulaziz University, Al-Kharj 11942, Kingdom of Saudi Arabia

6 Computational Systems Biology Research Group, Faculty of Medicine and Health Technology and BioMediTech, Tampere University, P.O.Box 553, 33101 Tampere, Finland

7 Institute for Systems Biology, 1441N 34th Street, Seattle, WA 98103-8904, USA

\author{
Abbreviations \\ HIC (1-(2-Hydroxy-5-nitrophenyl) (4-hydroxyphe- \\ nyl) methyl)indoline-4-carbonitrile) \\ P2Y1R Purinergic G-protein coupled receptor \\ AR Androgen receptor \\ $\mathrm{PCa} \quad$ Prostate cancer \\ GPCRs G protein-coupled receptors \\ PBS Phosphate-buffered saline \\ DMSO Diluted in dimethyl sulfoxide \\ MTT 3-(4,5-Dimethylthiazol-2-yl)-2,5-Diphenyltetra- \\ zolium Bromide \\ DAPI 4',6-Diamidino-2-phenylindole \\ AA Abiraterone acetate \\ PI Propidium iodide
}

\section{Introduction}

Prostate cancer $(\mathrm{PCa})$ is the most common malignant tumour diagnosed in men around the world [1]. It is known as the third leading cancer causing death in males, estimated at around 0.3 million patients' death per year [2]. However, 
metastatic PCa remains incurable due to its resistant characteristics against many chemotherapeutic drugs. Recently, second-generation anti-androgen therapy such as abiraterone acetate (AA), apalutamide, bicalutamide, etc. [3-7] is considered as a potential therapy for treating $\mathrm{PCa}$. The research for novel strategies and regimens to treat $\mathrm{PCa}$ has being continued but reducing the doses of drugs and improving the patients' lives remains an open challenge.

Anti-androgen therapy is often utilized to treat $\mathrm{PCa}$ and increase the patients' survival $[8,9]$. In the early stage of $\mathrm{PCa}$, medical or surgical castration is the common method for patients treatment $[10,11]$. However, the disease can still progress and be resistant to the primary treatment. Such a type of cancer is called castrate-resistant PCa (CRPC) [12]. In androgen receptor (AR)-positive cell line (LNCap cells), the anticancer effect of androgen biosynthesis inhibitor AA was observed to occur via the degradation of the CYP17A1 enzyme. This cytochrome P450, family 17, subfamily A, polypeptide 1 enzyme is crucial for androgen-dependent cancers and hyperplasia [13, 14]. AA inhibits the production of androgens by interfering with the enzymes $\mathrm{C} 17 \alpha$ hydroxylase and C17-C20 lyase, which suppresses PCa cells growth and metastasis [15]. Based on the down-regulated mechanism of AA, the common hypothesis is that the drug reduces the expression of AR and inhibits AR signaling, which is the crucial antitumor activity of the drug [16]. The clinical studies reported promising results in Phase I and II trials of patients with metastatic CRPC tested [17, 18]. Thus, AA (Zytiga, Janssen Biotech Inc.) was accepted by the US Food and Drug Administration (FDA) for patients with metastatic CRPC who had received prior chemotherapy [19]. FDA later approved the use of AA tablets in combination with castration and prednisone for the treatment of metastatic high-risk castration sensitive PCa (CSPC) [20, 21]. We have previously found limited evidence of AA activity, at low concentrations of AA, in inhibiting the proliferation of AR-negative PC 3 and DU145 cells [22, 23]. Martina et al. reported that $2 \mu \mathrm{M}$ of AA did not show cell death in PC3 and DU145 after $96 \mathrm{~h}$ treatment [22]. Additionally, it is evident that treatment of $30 \mu \mathrm{M} \mathrm{AA}$ can induce apoptosis on PC3 cell death [23]. On the other hand, purinergic receptor $1\left(\mathrm{P} 2 \mathrm{Y}_{1} \mathrm{R}\right)$ is highly expressed in PC3 and DU145 cells in both normal and cancer cells [24-27]. The activation of $P 2 Y_{1} R$ is suggested as a therapeutic target for suppressing PCa cell growth [26]. For example, MRS 2365, a selective agonist of P2Y1R, decrease cell proliferation and increase apoptotic cells' and Caspase 3 's activities in PC3 cells [26]. Recently, we designed and synthesized a P2Y $\mathrm{Y}_{1} \mathrm{R}$ agonist, 1-(1-((2-hydroxy-5-nitrophenyl)(4-hydroxyphenyl)methyl)indoline-4-carbonitrile (HIC) to activate the $\mathrm{P} 2 \mathrm{Y}_{1} \mathrm{R}$ signaling [28-30]. HIC is a time- and dose-dependent selective inhibitor of PC 3 and DU145 cell growth [28]. In addition, the activation of P2Y1R induces apoptosis, Caspase 3/7 activity, and ROS production in these cell lines [28]. Although the activity of HIC was identified as a potential drug-like compound again the growth of $\mathrm{PC} 3$ and DU145, the combinatorial effect of HIC along with any known clinical drug is yet to be investigated.

In this work, we aim to investigate the combinatorial effect of HIC and AA in the treatment of PC3 and DU145 cells. Here we measure the PCa cell death in a dose- and time-dependent manner, and colony formation. We have also measured the combinational index (CI) for the combinatorial activity of HIC and AA. Further, the anticancer and anti-metastasis effects were evaluated by apoptosis, caspase $3 / 7$, ROS formulation, wound healing, and invasion assay. Finally, we have also measured the combinatorial effect of HIC and AA on PCa cell phase arrest. The comprehensive in vitro evaluation of combined HIC and AA of the present study will provide a basis for future clinical studies.

\section{Materials and methods}

\section{Preparation of chemicals}

Compound 1-(1-((2-hydroxy-5-nitrophenyl)(4-hydroxyphenyl)methyl)indoline-4-carbonitrile (HIC) was synthesized as described previously [28]. Abiraterone acetate (AA) was purchased from Sigma-Aldrich (St. Louis, MO, USA). HIC and AA compounds were diluted at $100 \mu \mathrm{M}$ stocks in dimethyl sulphoxide (DMSO; Sigma-Aldrich).

\section{Cell culture}

PCa cell lines, PC3 and DU145, were cultured in Minimum essential medium eagle (MEME; Sigma-Aldrich). Noncancer cell lines HEK293 and MEF were maintained in Dulbecco's modified eagle medium-high glucose (DMEM; Sigma-Aldrich). Mediums were supplemented with $10 \%$ Fetal bovine serum (Biowest, Nuaille, France), $0.1 \mathrm{mg} / \mathrm{mL}$ streptomycin, $100 \mathrm{U} / \mathrm{mL}$ penicillin (Sigma-Aldrich), and $0.025 \mathrm{mg} / \mathrm{mL}$ amphotericin B (Sigma-Aldrich). Cells were grown at $37{ }^{\circ} \mathrm{C}$ in a humidified condition of $5 \% \mathrm{CO}_{2}$. Cells were passaged every 3-4 days using trypsin $1 \mathrm{X}$ (SigmaAldrich). To prepare cells for assays, cells were counted using trypan blue solution (Sigma-Aldrich) and countess II FL automated cell counter (ThermoFisher Scientific, Waltham, MA, USA).

\section{Cell proliferation and cytotoxicity assay}

To determine the sensitivity of PCa and noncancer cells to HIC and AA, cells were plated with a density of $1 \times 10^{4}$ cells/well in 96-well clear-bottom plates for $24 \mathrm{~h}$. Cells were dosed with various concentrations of $\operatorname{HIC}(1.25,2.5,5,7.5$, 15 , and $40 \mu \mathrm{M})$ and $\mathrm{AA}(5,10,20,30,40$, and $50 \mu \mathrm{M})$ for 
48 h. For the combinational drug model, PCa cell lines and noncancer cells were seeded in 96-well clear-bottom plates at a density of $1 \times 10^{4}$ cells/well for $24 \mathrm{~h}$ incubation. PC3 and DU145 cells were incubated with DMSO, HIC (1, 5, 10, 15, and $20 \mu \mathrm{M})$, AA $(3,15,30,45$, and $60 \mu \mathrm{M})$, or combination of HIC and AA for $48 \mathrm{~h}$. HEK293 and MEF cells were treated with $\mathrm{HIC}(1,5,10$, and $15 \mu \mathrm{M})$ and AA $(3,15,30$, and $45 \mu \mathrm{M}$ ) together. After $48 \mathrm{~h}$ treatment, cell death was determined using MTT cell proliferation and cytotoxicity assay kit (Bosterbio, CA, USA) as described previously [28]. Briefly, the cells were labelled with MTT labelling reagent $(0.5 \mathrm{mg} / \mathrm{mL}$ MTT reagent final concentration in phosphatebuffered saline, PBS) and incubated for $4 \mathrm{~h}$ in a humidified chamber. Then, formazan solubilization solution was added to each well and kept for $4 \mathrm{~h}$ in a dark condition. Treatments were carried out in triplicate. The optical densities (OD) of the supernatants were measured at $570 \mathrm{~nm}$ using a Magellan ${ }^{\mathrm{TM}}$ microplate reader (Tecan Group Ltd., Switzerland). The inhibitory effects of drugs were calculated using the equation given below,

\%inhibition $=\frac{A_{c}-A_{t r}}{A_{c}} \times 100$

where $A_{c}$ is the cell number of untreated cells, and $A_{t r}$ is the cell number of drugs treated cells. DMSO treated groups was considered as the vehicle control.

\section{Combination therapy assays}

The mechanism of drug interaction was determined using the combination index (CI). CI values were calculated using the CompuSyn software (ComboSyn Inc., Paramus, NJ, USA) following the below equation [31, 32].

$C I=\frac{(D 1)}{(D x) 1}+\frac{(D 2)}{(D x) 2}$

(Dx)1 and (Dy) 2 are the concentration of each drug required to produce the same effects as the effect produced by doses D1 and D2 in the combination [(D1)+(D2)]. CI values $<0.9,0.9<\mathrm{CI}<1.1$, and $1.1<\mathrm{CI}$ indicate synergistic, additive, and antagonistic effect of two drugs, respectively [33].

\section{Pharmacokinetic assay}

PC3 and DU145 cells were seeded in a 96-well plate at $1 \times 10^{4}$ cells/well. After $24 \mathrm{~h}$ incubation, PCa cells were treated with DMSO, $10 \mu \mathrm{M}$ HIC, $30 \mu \mathrm{M}$ AA, and $10 \mu \mathrm{M}$ $\mathrm{HIC}+30 \mu \mathrm{M}$ AA for 24,48 , and $72 \mathrm{~h}$ in an incubator. MTT cell proliferation and cytotoxicity assay kit were used to determine cell death. Inhibition percentage was analyzed using Eq. 1 for cell viability assay. DMSO sample was used as vehicle control.

\section{Colony assay}

PC3 and DU145 cells were seeded at 500 cells per well in six-well plates and incubated overnight. The cells were then treated with DMSO, $10 \mu \mathrm{M} \mathrm{HIC}, 30 \mu \mathrm{M}$ AA, or with combinations of HIC and AA. The media with and without drugs were refreshed every 3 days. After incubation for 12 days, the plates were washed gently two times with PBS. Colonies were then treated with fixing solution $(3.7 \%$ paraformaldehyde in PBS) for $10 \mathrm{~min}$ in RT. The colonies were washed two times with PBS and stained with a $0.05 \%$ crystal violet solution for $10 \mathrm{~min}$ at room temperature. Images were captured under a microscope. Colonies over 50 cells were counted directly using an Axiovert $200 \mathrm{M}$ microscope (Carl Zeiss, Germany). Survival fraction was measured using Eq. 3. DMSO-treated samples were considered vehicle samples.

Inhibitory ratio $(\%)=\frac{\text { No. of colonies treated with drugs }}{\text { No. of cell treated with vehicle }} \times 100 \%$

\section{4,6-Diamidino-2-Phenylindole, dihydrochloride (DAPI), Annexin V, and propidium iodide (PI) staining assay}

To determine the induction of apoptotic and necrosis by that target drugs, we carried out the cell apoptosis assay using a dead cell apoptosis kit (Sigma-Aldrich) and DAPI staining (ThermoFisher Scientific). PC3 and DU145 cells were plated in a six-well plate with a density of $5 \times 10^{5}$ cells/well. After $24 \mathrm{~h}$ incubation, cells were incubated with DMSO, $10 \mu \mathrm{M}$ HIC, and/or $30 \mu \mathrm{M}$ AA for $48 \mathrm{~h}$. The cells were collected with PBS and then incubated with $50 \mu \mathrm{L} 1 \mathrm{X}$ Annexin-binding buffer from the kit for $15 \mathrm{~min}$ in the dark condition. Then $5 \mu \mathrm{L}$ FITC conjugated Annexin $\mathrm{V}, 1 \mathrm{ng} / \mathrm{mL}$ PI, and $300 \mathrm{nM}$ DAPI was added to the cell suspension for $15 \mathrm{~min}$ in an incubator. The fluorescence images of cells were captured using EVOS FL (ThermoFisher Scientific) under $20 \times$ objective for each analysis. The fluorescence microscopy image data was analyzed to find out the differences in the plasma membrane integrity and permeability using Annexin V/PI dual staining. We have integrated both the semi-automated image processing along with manual counting to extract the fluorescence intensity values and thus measured the percentage of apoptotic and necrotic cells. 


\section{Caspase $3 / 7$ activity}

To determine the caspase 3/7 activity, PC 3 and DU145 cells were seeded in 96-well white plates at a density of $1 \times 10^{4}$ cells/well overnight. The cells were treated with DMSO, $10 \mu \mathrm{M}$ HIC, $30 \mu \mathrm{M}$ AA, and combinational $10 \mu \mathrm{M}$ HIC and $30 \mu \mathrm{M}$ AA for $5 \mathrm{~h}$. AA is the suitable control which not only act as a anti-androgen therapy for treating prostate cancer, but also functions as a caspase- 3 inhibitor. Caspase 3/7 was measured by using a Caspase-Glo®3/7 assay kit (Promega, Madison, WI, USA) following the manufactural protocol. Caspase-Glo reagent was added to the cells and then incubated in an incubator for $1 \mathrm{~h}$. The luminescence of the samples was measured using a Magellan ${ }^{\mathrm{TM}}$ microplate reader. The fold change of Caspase 3/7 activity was determined using the below equation,

Fold increase $=\frac{L_{\text {test }}-L_{\text {blank }}}{L_{\text {control }}-L_{\text {blank }}}$

where: $L_{\text {test }}$ is the luminescence of drugs treated wells; $L_{\text {blank }}$ is the luminescence of untreated wells and; $L_{\text {control }}$ is the luminescence of the unstained wells.

\section{ROS assay}

PC3 and DU145 cells were plated in 12-well plates with a density of $1 \times 10^{5}$ cells/well overnight. The cells were treated with $10 \mu \mathrm{M}$ HIC, $30 \mu \mathrm{M} \mathrm{AA}, 10 \mu \mathrm{M} \mathrm{HIC}+30 \mu \mathrm{M}$ AA, and $10 \mathrm{mM}$ hydrogen peroxide $\left(\mathrm{H}_{2} \mathrm{O}_{2}\right)$ as a positive control for ROS for $5 \mathrm{~h}$. The cells were collected and then incubated with $20 \mu \mathrm{M}$ 2',7'-dichlorodihydrofluorescein diacetate (H2DCFA) (Sigma-Aldrich) for $30 \mathrm{~min}$ in the dark condition. The stained cells were washed 2 times with PBS and incubated in the culture medium for $20 \mathrm{~min}$ in an incubator. The fluorescence of ROS products was measured at $485 \mathrm{~nm}$ (excitation) and $538 \mathrm{~nm}$ (emission) by a Magellan ${ }^{\mathrm{TM}}$ microplate reader. The fold change of ROS production was calculated according to Eq. 5 .

Fold change $=\frac{F_{\text {test }}-F_{\text {blank }}}{F_{\text {control }}-F_{\text {blank }}}$

where: $F_{\text {test }}$ is the fluorescence of drugs treated cells; $F_{\text {control }}$ is the fluorescence of untreated cells and; $F_{\text {blank }}$ is the fluorescence of unstained cells.

\section{Cell cycle analysis}

PC3 and DU145 cells were plated in a 6-well plate at the density of $5 \times 10^{6}$ cells/well. After $24 \mathrm{~h}$ incubation, the cells were dosed with DMSO, $10 \mu \mathrm{M}$ HIC, $30 \mu \mathrm{M}$ AA, or the combination of HIC and AA for $48 \mathrm{~h}$. Cell phases were determined using a propidium iodide kit (Sigma-Alrich). The cells were washed two times with cold PBS and then fixed in $70 \%$ ethanol on ice for $10 \mathrm{~min}$. Subsequently, the cells were dyed in $200 \mu \mathrm{L}$ of PI-Triton-RNase solution $(20 \mu \mathrm{g} / \mathrm{mL}$ PI, $0.2 \mathrm{mg} / \mathrm{mL}$ RNase, and $0.1 \%$ Triton X-100 in PBS) for $15 \mathrm{~min}$ in the dark condition. Fluorescence images were captured using EVOS FL at $20 \times$ magnification. The images were analyzed using CellProfiler software 4.0 [34] and cell cycle phases were calculated using MATLAB R2020a (MathWorks Ltd., MA, USA).

\section{Wound-healing assay}

PC3 and DU145 cells were seeded in six-well plates with a density of $1.5 \times 10^{6}$ cells/well for $24 \mathrm{~h}$. At $80-90 \%$ confluence, the wound was made with $200 \mu \mathrm{L}$ pipette tips. The floating cells were removed by washing the plates two times with warm PBS. The cells were then incubated with DMSO, $10 \mu \mathrm{M} \mathrm{HIC}$, and/or $30 \mu \mathrm{M} \mathrm{AA}$ in $1 \%$ FBS media for $24 \mathrm{~h}$. The images of the migrated cells into the wound surface were captured using EVOS imaging systems. The wound areas were measured using ImageJ software 1.52 (National Institutes of Health, USA). The wound closure was calculated using Eq. 6.

$W_{\text {change }}=\frac{W_{0-D}-W_{24-D}}{W_{0-C}-W_{24-C}} \times 100 \%$

where: $W_{O-D}$ is the scratch area in samples treated with drugs at the starting point; $W_{24-D}$ is the scratch area in samples treated with drugs after $24 \mathrm{~h}$ incubation; $W_{0-C}$ is the scratch area in vehicle groups at the starting point and; $W_{24-C}$ is the scratch area in vehicle groups after $24 \mathrm{~h}$ incubation. DMSO treated groups were considered as the vehicle groups.

\section{Invasion assay}

Transwells (6-well type, pore size $8 \mu \mathrm{m}$ ) were coated with Corning® Matrigel ${ }^{\circledR}$ Basement Membrane Matrix (Corning, NY, USA) for $2 \mathrm{~h}$ in an incubator. PC3 and DU145 cells $\left(5 \times 10^{5}\right.$ cells/well $)$ were seeded to the upper chamber in the absence or presence of HIC and AA in 1\% FBS media. The lower chamber was completely filled with FBS medium. After $24 \mathrm{~h}$ incubation, the chambers' membranes were treated with Fixing solution (3.7\% paraformaldehyde in PBS) for $10 \mathrm{~min}$. Next, the chambers were washed gently with warm PBS. The membranes with invaded cells were stained with $0.5 \%$ crystal violet in $2 \% \mathrm{EtOH}$. After 5 min, the membranes were washed with PBS and kept dry at room temperature. Five random fields of the membranes were observed. Invaded cells were calculated based on the average number of cells from five random areas. Data were 
presented as the percentage of the number of invaded cells based on the vehicle group.

\section{Statistical analysis}

All the experiments were repeated three or five times with the same biological and technical conditions. The results are represented as means \pm standard error of the mean (SEM) using IBM SPSS Statistics version 26. Differences between samples groups and experimental conditions were analyzed using one-way ANOVA followed by GraphPad Prism 8.0 software. Statistical significance was considered with $* p<0.05$.

\section{Results}

\section{Sensitivity of PCa and noncancer cells to HIC and AA}

To assess the effective concentrations of HIC and AA (Fig. 1A) on cell death, PCa and non-cancer cells were incubated with increasing concentrations of $\mathrm{HIC}$ and AA for $48 \mathrm{~h}$ and cell viability was determined by MTT assay. Results show that HIC decreased cellular growth in a concentration-dependent manner compared to vehicle-treated cells (Fig. 1B). At a dosage of $40 \mu \mathrm{M}$ HIC, PC3 and DU145 cells were inhibited to $\sim 80 \%$ after $48 \mathrm{~h}$ treatment. At the same concentrations of HIC, the cell growth of HEK293 and MEF cells was similar to DMSO control groups (Fig. 1B). The $\mathrm{IC}_{50}$ values of $\mathrm{HIC}$ for PC 3 and DU145 cells were determined as $15.98 \mu \mathrm{M}$ and $15.64 \mu \mathrm{M}$, respectively. Conversely, AA showed lower inhibitory effects on the growth of $\mathrm{PCa}$ cells than HIC at $40 \mu \mathrm{M}$ after $48 \mathrm{~h}$ treatment (Fig. 1C). The cell death was observed at about $34.6 \pm 1.8 \%$ and $43.6 \pm 1.9 \%$ in PC3 and DU145 cells at $40 \mu \mathrm{M}$ AA treatment. These results are consistent with prior findings that AA had slight inhibitory effects on cell proliferation of PC3 and DU145 cells which have low expression of AR [22, 23]. Therefore, our results suggest that PC 3 and DU145 cells are more sensitive to HIC than AA.

\section{HIC and AA cotreatment reduces cell growth in PCa cells}

Next, to understand the effect of combined drugs treatment, PC 3 and DU145 cells were treated with HIC and AA alone and the combination of $\mathrm{HIC}$ and $\mathrm{AA}$ (HIC + AA) at specific concentrations, as described in the methods section. Based on the sensitivity of HIC and AA on PC 3 and DU145 cells, HIC and AA concentrations were adjusted to maintain a constant 1:3 ratio of HIC:AA for PC3 and DU145 cells. When HIC and AA were combined, a dramatic reduction in cell viability was observed (Fig. 2A, B). Cell death in both PC3
A
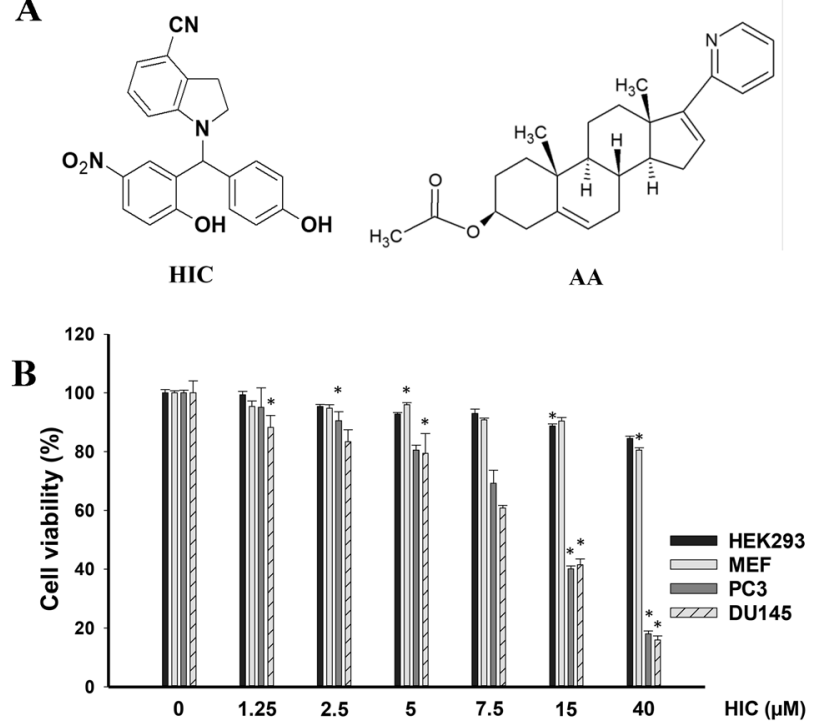

C



Fig. 1 Sensitivity of PCa and noncancer cells to HIC and AA. Structure of HIC and AA (A). Percentage of cell viability with HIC treatment (B) and AA treatment (C) were determined using MTT assay. PC3, DU145, HEK293, and MEF cells were treated with increasing doses of HIC and AA for $48 \mathrm{~h}$. Values are presented as the means $\pm \mathrm{SD}$ of three biological experiments. $* p<0.05$ relatives to DMSO-treated group

and DU145 cells $~ 50 \%$ was observed when in presence of $15 \mu \mathrm{M}$ HIC or $45 \mu \mathrm{M}$ AA (Fig. 2A, B). At an intermediate dosage of combined $10 \mu \mathrm{M}$ HIC and $30 \mu \mathrm{M}$ AA cell proliferation was inhibited more than $50 \%$ in both cell lines. These results identified that the co-treatment of $\mathrm{HIC}+\mathrm{AA}$ induced stronger inhibitory effects on cell growth in PCa cells than using a single drug treatment. Subsequently, HEK 293 and MEF cells treated with the same concentrations of two drugs did not show a significant decrease in cell survival compared with vehicle groups (Fig. 2C). The synergistic effect of HIC and AA was analyzed based on CI values. Table 1 shows the CI values for DU145 and PC 3 cells treated with the combination of HIC and AA. CI values less than 0.9, from 0.9 to 1.1 , or more than 1.1 allow indicating the quantification of synergism, additive, or antagonism of two drugs, respectively. In addition, the combination of $10 \mu \mathrm{M}$ HIC and $30 \mu \mathrm{M}$ AA was less sensitive to the non-cancer cells 
A

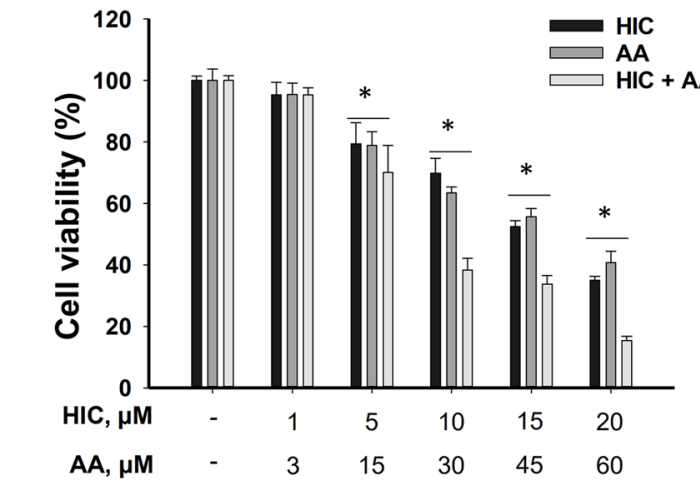

HIC + AA, $\boldsymbol{\mu M} \quad-\quad 1+3 \quad 5+15 \quad 10+30 \quad 15+45 \quad 20+60$

C



$\mathbf{E}$

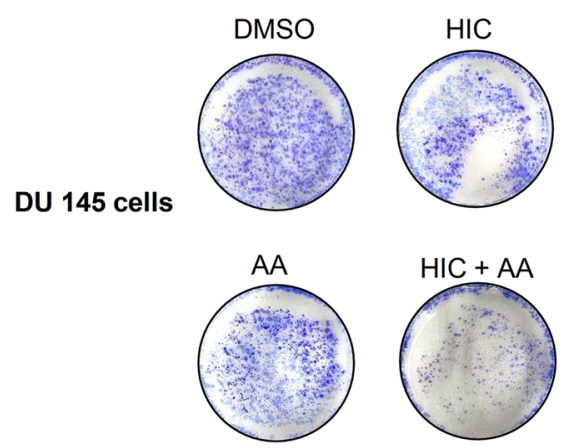

Fig. 2 HIC and AA co-treatment reduces cell growth in PCa cells. Percentage of PC3 (A) and DU145 (B) cells viability in the presence of HIC and AA, alone or in combination with indicated concentrations. Percentage of cell viability for HEK293 and MEF cells with co-treated HIC and AA (C). Representative images of PC3 (D) and
B

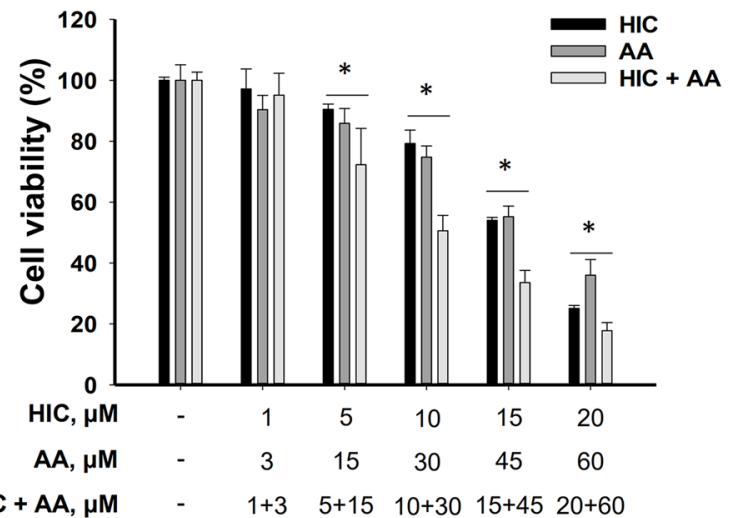

$\mathrm{PC}-3$ cells
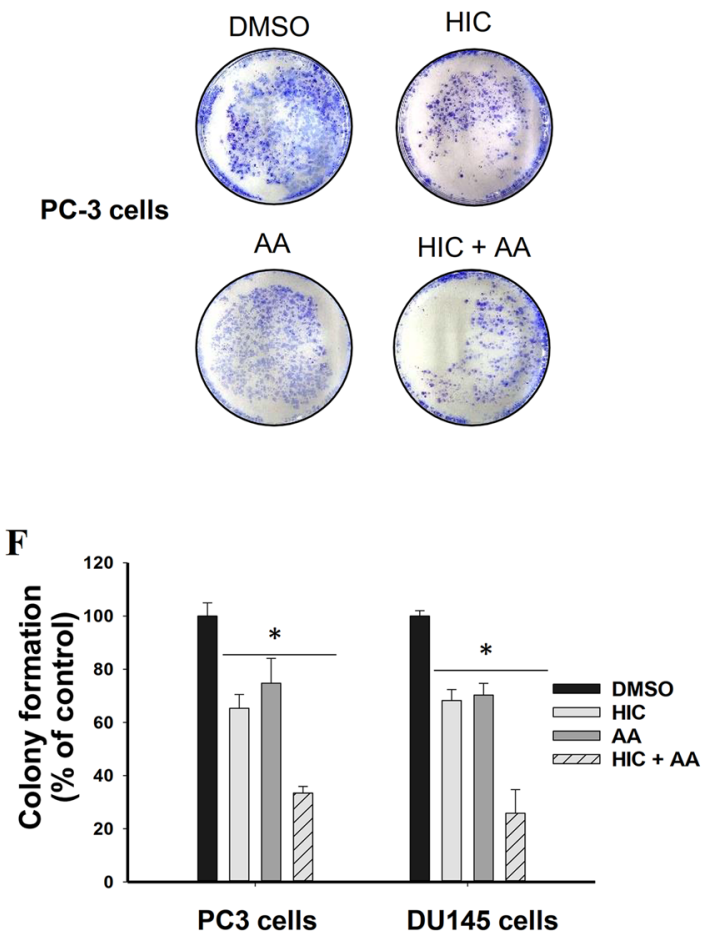

DU145 (E) cells treated with HIC, AA, or a combination of both in Clonogenic survival assay. The bar graph presented the colony formulation of PCa cells with HIC and AA treatment based on the normalization with DMSO groups $(\mathbf{F})$. Data were analyzed by one-way ANOVA; $* p<0.05$ relatives to DMSO-treated group
Table 1 Combination index (CI) values for combined use of $\mathrm{HIC}$ and AA in PC3 and DU145 cells

\begin{tabular}{llllllllll}
\hline Cell lines & HIC $\mu \mathrm{M}$ & AA $\mu \mathrm{M}$ & Effect $\%$ & CI & Cell lines & HIC $\mu \mathrm{M}$ & AA $\mu \mathrm{M}$ & Effect \% & CI \\
\hline PC3 cells & 1 & 3 & 4.88 & 2.02 & DU145 cells & 1 & 3 & 6.71 & 1.89 \\
& 5 & 15 & 27.71 & 1.33 & & 5 & 15 & 30.02 & 1.49 \\
& 10 & 30 & 49.43 & 1.11 & 10 & 30 & 61.63 & 0.85 \\
& 15 & 45 & 66.45 & 0.88 & & 15 & 45 & 66.23 & 1.06 \\
& 20 & 60 & 82.23 & 0.57 & & 20 & 60 & 84.69 & 0.53 \\
\hline
\end{tabular}


survival (Fig. 2C) than for PCa cells (Fig. 2A, B). Therefore, these combinatorial concentrations were selected to perform further experiments.

To determine the anticancer effect of combined HIC and AA, the effects of both drugs on tumour cell clonogenicity in PC3 and DU145 cells were examined. Cells were treated with HIC and AA as described in the methods section. As shown in Fig. 2D, E, cotreatment with HIC and AA markedly inhibited PCa colony formation more than in single drugs treatment. In detail, $\mathrm{PC} 3$ colony formation was reduced by $34.7 \%, 25.3 \%$, and $59.5 \%$ by HIC, AA, and HIC + AA combined treatments, respectively (Fig. 2F). The effect of HIC and AA cotreatment was 1.7 and 2.4 times more effective than HIC and AA alone. Similarly, the decrease of DU145 colonies was observed as $31.7 \%, 23.7 \%$, and $60.1 \%$ by the presence of HIC, AA, and HIC + AA, respectively (Fig. 2F). The combined use of HIC and AA increased 1.5 to 2 times the effect of single AA in both PC 3 and DU145 cells. These data purpose that the combinatorial treatment of $\mathrm{HIC}+\mathrm{AA}$ can stop the colony formation. It is worth to suggest that the combinatorial treatment can stop the PCa cells division in vitro.

\section{Combination of HIC and AA inhibits the proliferation of PCa cells in a time-dependent manner}

Growth kinetics of cells treated with HIC, AA and HIC + AA were measured as described in the methods section to understand the effect of using combined drugs over time. As shown in Fig. 3A, the cell proliferation in treated PC 3 cells was significantly lower in HIC and AA treatment than in the control group over time. The inhibition on the proliferation of PC 3 cells was about $11.7 \%, 30.1 \%$, and $54.4 \%$ by HIC, and about $4.6 \%, 20.1 \%$, and $59.2 \%$ by AA treatments, at $24 \mathrm{~h}, 48 \mathrm{~h}$, and $72 \mathrm{~h}$ respectively. However, a stronger inhibitory effect was observed in the combined use of HIC and AA groups after $24 \mathrm{~h}$ treatment. HIC and AA cotreatment induced $10.6 \%, 57.6 \%$, and $74.4 \%$ of PC3 cell growth at $24 \mathrm{~h}, 48 \mathrm{~h}$, and $72 \mathrm{~h}$, respectively. Similarly, in DU145 cells, the cell proliferation was decreased from 50.5 to $97.3 \%$ progressively from 24 to $72 \mathrm{~h}$ on the treatment with HIC and AA. However, the impact of HIC and AA co-presence showed a reduced proliferation to $90.3 \%, 40.5 \%$, and $17.5 \%$ at 24,48 , and $72 \mathrm{~h}$, respectively. These findings suggest that the proliferation was inhibited on treatment with HIC + AA stronger than in single-drug treatments. In addition, HIC and AA could inhibit cancer cell proliferation by increasing the treatment time.

\section{Combinatorial effect of HIC and AA induces apoptosis through caspase $3 / 7$ activation and ROS production}

To investigate whether synergistic loss of cell viability in PCa cells was related to the apoptotic process or not, we further examined the effect of drugs by Annexin V-affinity assay. Post $48 \mathrm{~h}$ of treatment, the fluorescent microscope images of PCa cells were captured to expose the presence of apoptotic (green) and necrotic (red) cells (Fig. 4). As shown in Fig. 4A, co-treatment of HIC and AA significantly increased the number of apoptotic cells (green) more than DMSO groups after 2 days of treatment. The increase of apoptotic cells in PC 3 cells was observed $12.2 \%$ and $14.2 \%$ by HIC and AA single treatment, respectively, whereas the combinatorial drugs induced $40.4 \%$ apoptotic population (Fig. 4A). Similarly, the induction of apoptotic responses in DU145 cells was $34.8 \%$ in the co-treatment of HIC and AA whereas $15.2 \%$ and $14.3 \%$ increases were determined in treatments with $\mathrm{HIC}$ and AA, respectively. These findings suggest that AA in combination with HIC induced apoptosis in PC3 and DU145 cells in agreement with the observed inhibitory effects on cell survival.

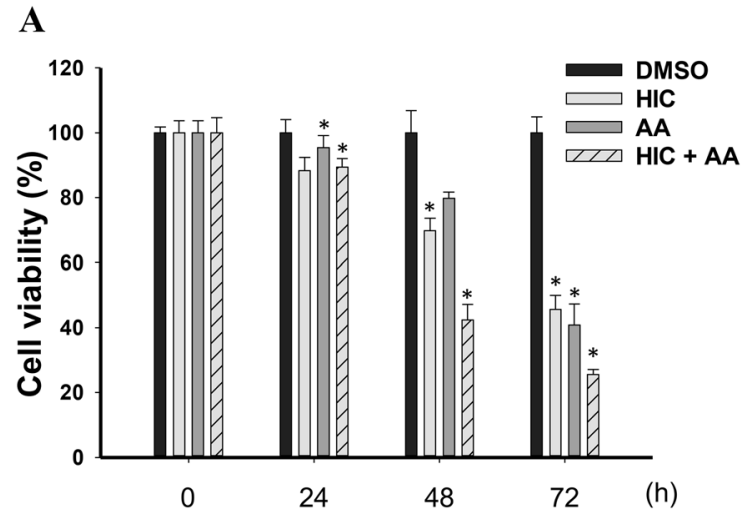

Fig. 3 Combination of HIC and AA inhibits the proliferation of PCa cells in a time-dependent manner. Percentage of cell viability in $\mathbf{A}$ PC3 and B DU145 cells treated with HIC, AA, and HIC + AA combi-
B

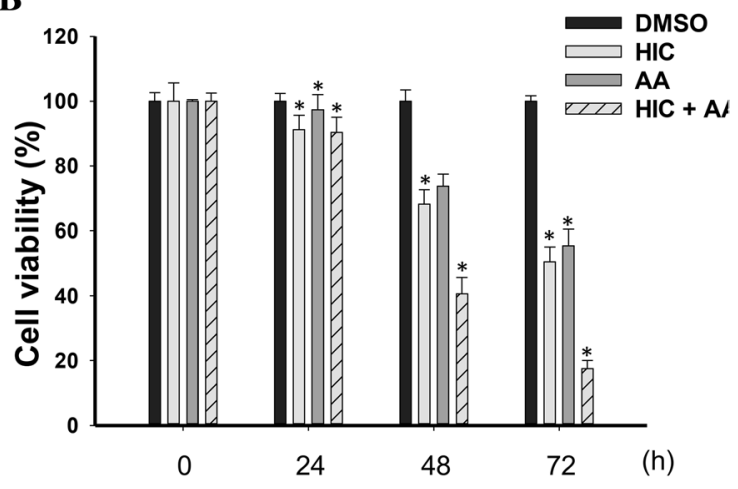

nation for 24,48 , and $72 \mathrm{~h}$. The percentage of cell survival was normalized to DMSO groups. The experiment was performed with $\mathrm{n}=6$. Statistical significance was considered with $* p<0.05$ 



C

D
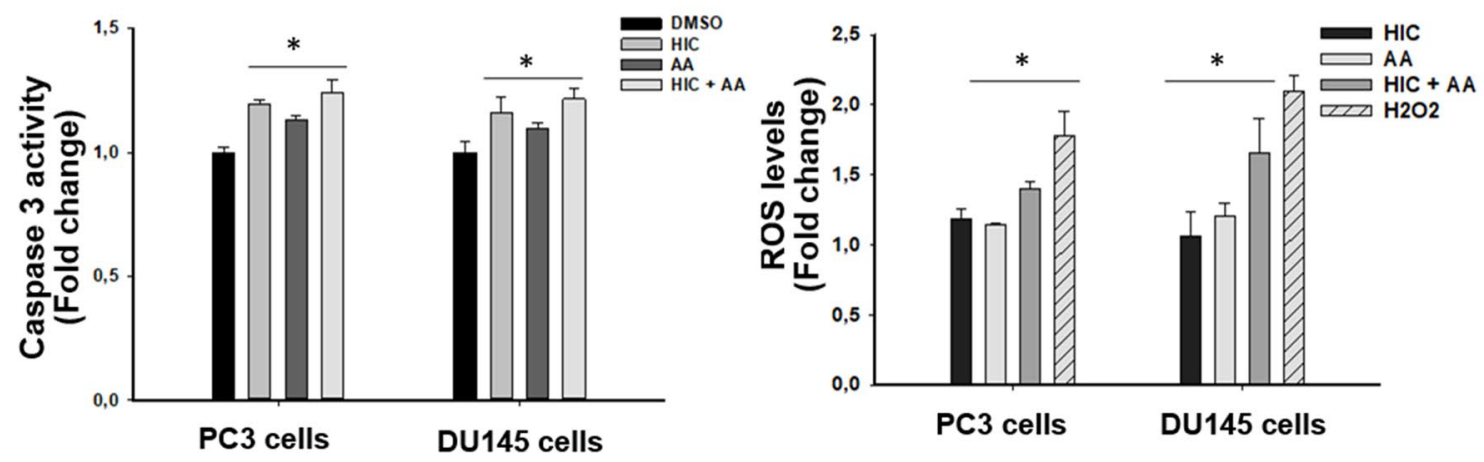

Fig. 4 Combinatorial effect of HIC and AA induces apoptosis, caspase 3/7 activation, and ROS production. Representative images of PC3 (A) and DU145 (B) cells stained with DAPI/Annexin-V/PI in DMSO, HIC, AA, and cotreated drugs condition. Percentage of apoptotic and necrotic cells were presented in the corresponding conditions. C Fold changes of caspases 3/7 activity in PC3 and DU145

cells compared to DMSO groups. D Fold change of ROS production in PC3 and DU145 cells were calculated using fluorescence intensities based normalized against DMSO control. Biological and technical replicates were performed to analyze the results, with mean $\pm \mathrm{SD}$, $* p<0.05, \mathrm{n}=6$ 
The activation of Caspase 3/7 is known as the crucial player in cell death and apoptosis [35]. To investigate the anticancer effect of HIC and AA, a Caspase 3/7 assay was performed in PC3 and DU145 cells. On treatment with the combination of HIC and AA, PC3 and DU145 cells have shown increasing fold changes of Caspase 3/7 (Fig. 4C). We noticed an increase in fold change of caspase $3 / 7$ activity to 1.19 and 1.12 in HIC- and AA-treated PC3 cells, respectively, when compared to the vehicle group. Interestingly, the increase of Caspase 3/7 activity was observed in HIC and AA-cotreated PC3 cells with a fold change of about 1.24. Likewise, the activation of Caspase 3/7 in DU145 cells also increased to 1.15- and 1.09-fold change on treatment with HIC and AA whereas HIC + AA showed 1.21 caspase $3 /$ sevenfold change. The difference in the fold change of treated and untreated groups was considered as a statistical analysis through ANOVA test with $p<0.05$. These findings showed that the combined treatment with HIC and AA, induced more caspase activity than treatment with one of the single compounds. Moreover, HIC and AA could induce apoptosis through the Caspase 3/7 dependent signaling pathway. It is noted that caspase- 3 play a crucial role in the apoptosis process in various cell lines, which is primarily responsible for the cleavage of poly(ADP-ribose) polymerase (PARP) during cell death. In our previous study [36], we have reported the total gene expression profile of PC3 and DU145 cells treated with HIC compound. We found the downregulation of PARP10 and PARP12 expression in both the cell lines. Furthermore, PARP1 and PARP14 was also downregulated in PC3 cells, while PARP9 was downregulated in DU145 cells. These observations further support that caspase 3 is activated upon the treatment of HIC compound." The differential expression of PARP is plotted as graph and presented as a supplementary Fig. 1.

Accumulation of ROS at mitochondria is one of the apoptotic mechanisms in the intrinsic cell death pathway [37, 38]. A high level of ROS might damage proteins, nucleic acid, and result in oxidative stress and cellular dysfunctions [39]. In addition, ROS is known as a capable stimulator inducing cell cycle arrest and cell death in cancer therapeutics [40]. In order to investigate the effect of HIC and AA combination on PCa via ROS productivity, PC 3 and DU145 cells were treated with HIC, AA, and $\mathrm{H}_{2} \mathrm{O}_{2}$ (positive control). As shown in Fig. 4D, the fold change of ROS production increased in the presence of $\mathrm{HIC}$, AA, and $\mathrm{H}_{2} \mathrm{O}_{2}$ in both cell lines. The fold change of ROS was increased $~ 1.2$ in both HIC- or AA-treated PCa cells. HIC and AA co-treatment increased the fold change of ROS with 1.4 and 1.6 in PC 3 and DU145 cells, respectively. Therefore, ROS productivity was noticeably higher in HIC + AA-treated cells than in HIC- and AAtreated cells.

\section{Combined use of HIC and AA suppresses the $\mathbf{G} 1$ phase of the PCa cell cycle}

Apoptosis is the major cellular response that can regulate cell cycle arrest and induce cell death [41, 42]. To evaluate whether the combination of HIC and AA induces cell cycle distribution in PCa cells, cell cycle analysis was examined as described in the methods section. Fig. 5A, B exemplify fluorescence images of DNA content in each cell phase, treated by selected compounds. The cells were segmented to detect the distribution of each phase under different conditions. The proportion of the G1 phase of $\mathrm{PC} 3$ cells was increased after treatment with HIC and AA by $35.5 \%$ and $55.7 \%$, respectively, compared to the vehicle group with $16.4 \%$ for the G1 phase. Interestingly the combined use of HIC with AA induced the highest G1 proportion to $75.1 \%$ (Fig. 5A). The transition of S phase of PC3 cells was not significantly different among vehicle, HIC, and AA treatment, about $34.0 \%$, $40.1 \%$, and $34.4 \%$, respectively. Interestingly, the distribution of G1 phase in DU145 cells was observed as the same as in PC 3 cells. A higher percentage of the G1 phase, $77.1 \%$, was observed in the combinatorial treatment of HIC and AA. The proportion of G1 phase in DU145 cells treated with HIC and AA was calculated as $44.5 \%$ and $60.5 \%$, respectively. Furthermore, in the S phase of DU145 cells, the percentage of the population in $\mathrm{HIC}, \mathrm{AA}$, and $\mathrm{HIC}+\mathrm{AA}$, and vehicle-treated cells was $30.0 \%, 15.0 \%, 9.0 \%$, and $24.0 \%$, respectively. Notably, a higher fraction of G1 phase arrest in both PC3 and DU145 cells was observed in HIC and AA cotreated groups. Taken together, the results suggested that the combined treatment of HIC and AA arrested the PCa cells at G1 proliferation phases, leading to higher suppression than the treatments with $\mathrm{HIC}$ and AA alone.

\section{Metastatic activity of PCa cells was inhibited by treatment with HIC and AA}

The cell migration and invasion are known as important characteristics of malignant tumour cells, thus inhibiting migration and invasion of cells are considered as crucial targets in developing new anticancer therapeutics [43, 44]. Here we performed the cell migration and invasion assay to investigate the effect of HIC and/or AA on PC3 and DU145 cells. As shown in Fig. 6A, the PCa cells were scratched and treated with drugs. The invaded areas of PCa cells after HIC + AA treatment decreased steadily after $12 \mathrm{~h}$ of incubation whilst it increased over time after DMSO treatment. $24 \mathrm{~h}$ of post-treatment, the invaded areas of PC 3 cells decreased to $23.5 \%, 27.1 \%$, and $46.4 \%$ by HIC, AA, and $\mathrm{HIC}+\mathrm{AA}$, respectively. Notably, a similar pattern was also observed in DU145 cells. The percentage of migrated cells in DU145 cells was reduced to $29.5 \%$ by HIC, $35.2 \%$ by AA, and $55.5 \%$ by HIC + AA treatment. In addition, to further 
Fig. 5 Combination of $\mathrm{HIC}$ and AA suppresses the G1 phase of the PCa cell cycle. PC3 and DU145 cells were treated with $\mathrm{HIC}$ and AA alone or in combination for $48 \mathrm{~h}$. Cells were fixed and stained with PI. Microscopic images of PC3- (A) and DU145- (B) treated cells were captured and analyzed to detect cell-cycle distribution. The percentage of cells in each phase was calculated and presented. Data is shown as mean $\pm \mathrm{SD}$, $* p<0.05, \mathrm{n}=6$

\section{A PC3 cells}


B

DU145 cells

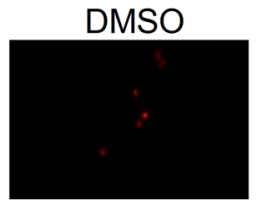

AA

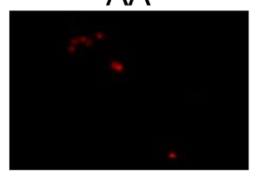

$\mathrm{HIC}$

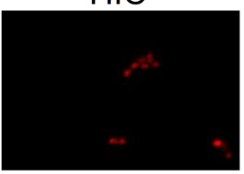

$\mathrm{HIC}+\mathrm{AA}$



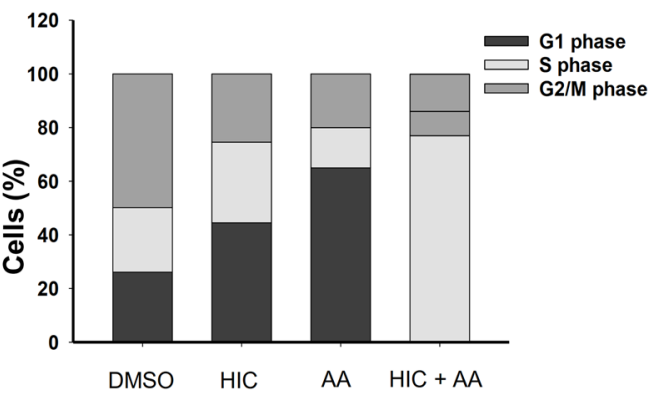

explore the anti-metastasis effect on the invaded cells, we performed the invasion assay with HIC and AA co-treatment. PC3 and DU145 cells were treated with HIC and AA and then measured the invaded activity via Matrigel-coated transwell after $24 \mathrm{~h}$ treatment. As shown in Fig. 6B, cell invasion decreased in both cells when drugs were present. A significant decrease caused by HIC and AA co-treatment was observed in DU145 cells. In detail, the invaded cells in DU145 cells were inhibited to $78.5 \%, 75.7 \%$, and $52.4 \%$ by HIC, AA, and HIC + AA treatments, respectively (Fig. 6B). These results demonstrate that the combination of both HIC and AA potentially inhibits cell migration and invasion of PCa cells.

\section{Discussion}

In the present study, we characterized the pharmacological activity of HIC, P2Y1 receptor agonist, in androgen-independent cancer cell lines models PC-3 and DU145. Former studies concerning HI, have served as proof of principle: PC-3 and DU145 cell growth inhibition was induced by HIC were the compound act as a 53 stabilizer in prostate cancer cells, however, the detailed molecular mechanism of HIC in combination with any clinical drugs are yet to be investigated [30]. Here, we investigated the potential mechanism involved in the inhibition of cell growth in AR-negative-cell lines, PC 3 and DU145, by AA and HIC co-treatments. Our results suggest that these cell lines were sensitive to HIC at the $\mathrm{IC}_{50}$ range of $15-18 \mu \mathrm{M}$ after $48 \mathrm{~h}$ treatment. The metastatic cell lines PC3 and DU145 which are both AR low and represent castrate-resistant metastatic disease, are equally responsive to HIC. AR-negative PC3 and DU145 cells exhibited comparably growth inhibition responses to the presence of AA.

The applied AA concentration of $40 \mu \mathrm{M}$ induced $~ 50 \%$ cell death after $48 \mathrm{~h}$ treatment. AA was minimally effective in killing PC3 and DU145 cells at the concentration utilized, but the combination of both compounds results in synergistic-induced loss of cell viability. Moreover, normal cell lines are less sensitive to the combined effects of HIC and AA than PCa cells in the same conditions. Concerning the apoptosis produced by the combination of HIC and AA, we showed that Caspase 3/7 activity and ROS formulation increased due to the synergic effect of the two drugs. One possible mechanism of cell death is cell cycle arrest. The cell phases arrested by AA and HIC in these cells have not been reported. Here, we found that the combination between HIC and AA suppressed the G1 phase in both cell lines.

Besides the numerous AR signaling events in PCa cells, chemotherapy widely exerts its anticancer effect by triggering apoptotic mechanisms of tumour cells [45]. A primary regulator of apoptosis is the tumour suppressor p53, which plays a key role in cell cycle control, genomic stability, and apoptosis [46]. Increased DNA fragmentation as well as downregulation of the cell survival factor surviving also 
Fig. 6 Inhibition of metastatic properties of PCa cells. A The wounds of PC3 and DU145 cells were created using a scratcher, and then cells were incubated with HIC, AA, alone or a combination of both.

Representative images were captured at 0 and $24 \mathrm{~h}$. A mark in these images was placed to locate the same area on the scratch. Percentage of relative wound closure was shown as a bar graph. B Invaded cells were captured under the microscope. The bar graph presented is the percentage of cell invasion based on DMSO groups. Experiments were repeated three times with technical repeats, $\mathrm{n}=6, * p<0.05$, ANOVA test
A

PC3 cells

O h

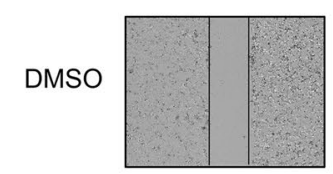

HIC

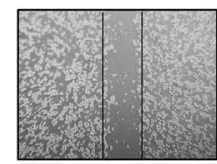

AA
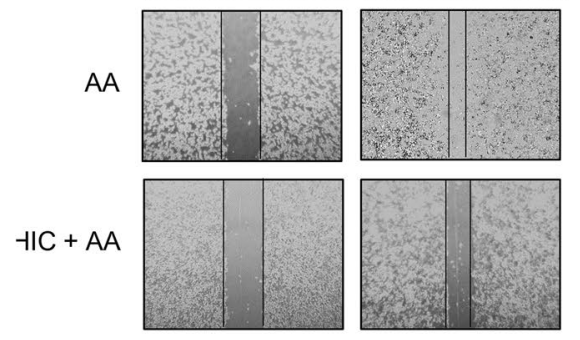

B
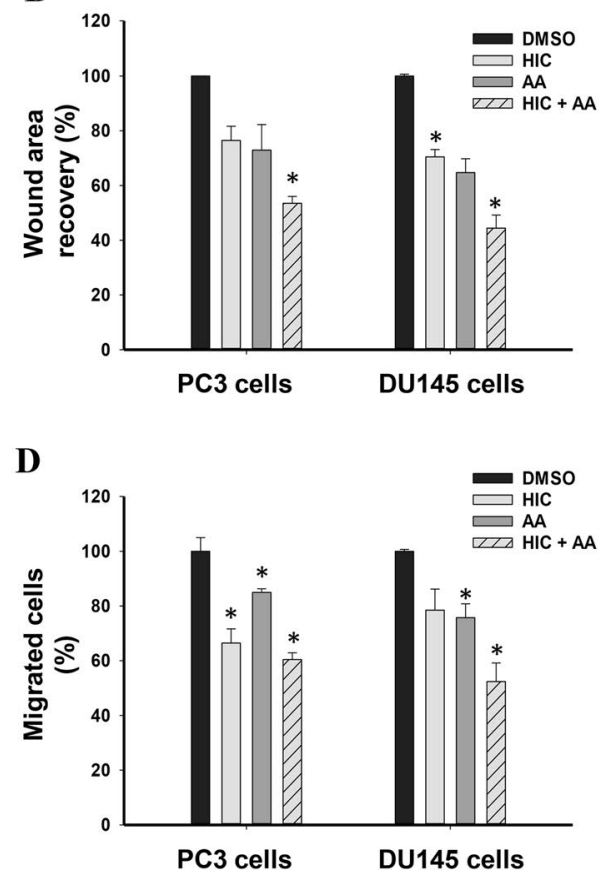

DU145 cells

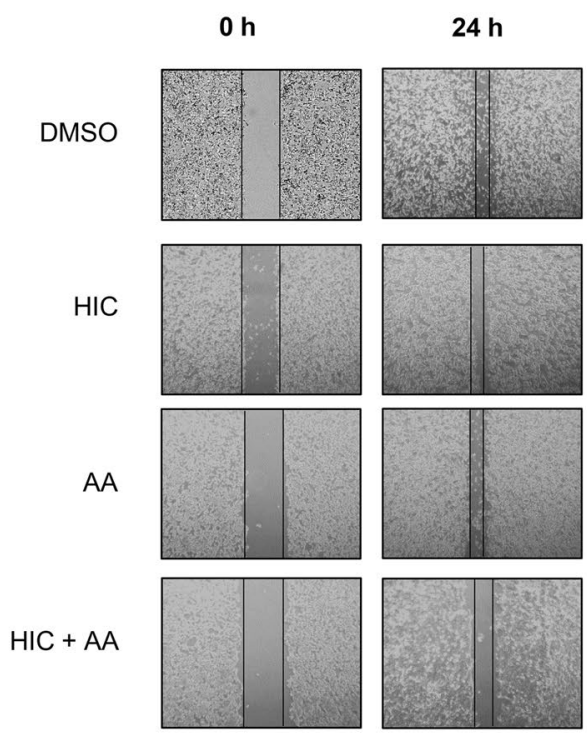

C

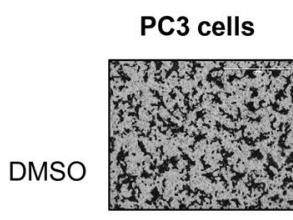

DU145 cells

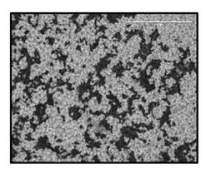

$\mathrm{HIC}$
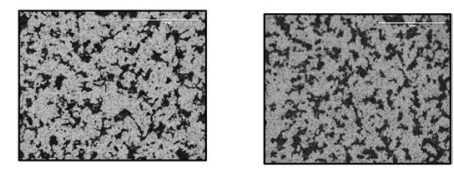

AA
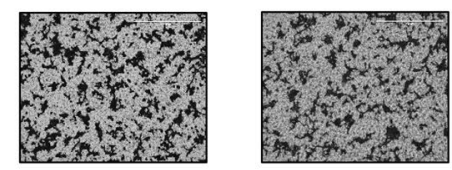

$\mathrm{HIC}+\mathrm{AA}$
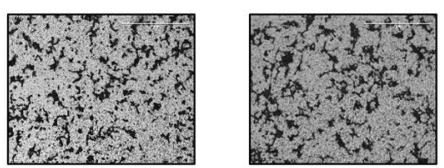

confirm the involment of execution of apoptotic mechanisms. Further, increased level of the cell cycle inhibitor p21 and the effector caspase 3 also confirms the role of apoptosis ativation [47], 48. From our previous studies, HIC was known to induce the stability of p53 and regulate p21 signaling in PCa cells. The decrease of mRNA levels was observed in $C D K 2, C y c l i n E, C y c l i n A, C D K 4$ in the incubation of HIC in PC3 and DU145 cells [30]. Interestingly, DNA fragment was determined as one factor in the HIC downregulation mechanism. Moreover, the levels of $B A X$, Caspase3, p21, and Survivin also increased in the presence of $30 \mu \mathrm{M}$ of AA after $48 \mathrm{~h}$ in PC3 cells [23]. In this work, our results showed the increase of Caspase $3 / 7$ activity and ROS production with the combined use of HIC and AA. Notably, the G1 phase was arrested by the synergic effect of HIC and AA after $48 \mathrm{~h}$. Taken together, our observations suggest that AA and HIC could mediate the cell death in PC3 and DU145 cells through the activation of apoptosis via p53, p21 signaling. AR signal is not the only rationale to explain the anticancer activity of AA in PCa cells. In addition, the presence of $\mathrm{HIC}+\mathrm{AA}$ potentially inhibited cell proliferation. Therefore, the combination of HIC and AA would be considered as a promising agent in the treatment of AR-negative PCa cells. In summary, the activation 
of the P2Y1 receptor by $\mathrm{HIC}$ and its combination with AA demonstrated that the HIC might be an attractive agent for the treatment of prostate cancer.

\section{Conclusion}

In summary, our results show that the HIC and AA induce apoptosis-mediated cell death through the activation of Caspase 3/7 and ROS production. The synergistic effect of HIC and AA affects prostate cancer cells proliferation in a timedependent manner, and their migration, invasion, colonyforming ability, and cell cycle progression in the G1 phase. More importantly, the combination of two compounds, a P2Y1 receptor agonist and an androgen receptor inhibitor, is found to be a potential combinatorial drug to overcome prostate cancer.

Supplementary Information The online version contains supplementary material available at https://doi.org/10.1007/s10495-022-01716-1.

Acknowledgements We thank Tampere University for providing all instrumental facility.

Author contributions NRC synthesized and characterized the compounds; HL executed the experiments and data analysis. AM and TR involved in technical discussion, quality check and manuscript editing. OY and MK conceived and managed all studies. All the authors contributed to writing the manuscript.

Funding HL acknowledge the TUT-RAE for the project grant support.

Data availability The datasets generated analysed during the current study are available from the corresponding author on reasonable request.

\section{Declarations}

Conflict of interest The authors declare that they have no competing interests.

Ethical approval Not applicable.

Informed consent Not applicable.

Consent for publication Not applicable.

Open Access This article is licensed under a Creative Commons Attribution 4.0 International License, which permits use, sharing, adaptation, distribution and reproduction in any medium or format, as long as you give appropriate credit to the original author(s) and the source, provide a link to the Creative Commons licence, and indicate if changes were made. The images or other third party material in this article are included in the article's Creative Commons licence, unless indicated otherwise in a credit line to the material. If material is not included in the article's Creative Commons licence and your intended use is not permitted by statutory regulation or exceeds the permitted use, you will need to obtain permission directly from the copyright holder. To view a copy of this licence, visit http://creativecommons.org/licenses/by/4.0/.

\section{References}

1. Leitzmann MF, Rohrmann S (2012) Risk factors for the onset of prostatic cancer: age, location, and behavioral correlates. Clin. Epidemiol 4:1-11

2. Siegel RL, Miller KD, Jemal A (2020) Cancer statistics, 2020. CA Cancer J Clin. https://doi.org/10.3322/caac. 21590

3. Ruterbusch JJ, Bylsma LC, Barlev A et al (2017) Bicalutamide treatment patterns in elderly prostate cancer patients: a historical cohort study using the surveillance, epidemiology and end results program (SEER)-medicare database. Val Heal 20(5):A127-A128

4. Rathkopf DE, Scher HI (2018) Apalutamide for the treatment of prostate cancer. Expert Rev Anticancer Ther. https://doi.org/10. 1080/14737140.2018.1503954

5. Scher HI, Fizazi K, Saad F et al (2012) Increased survival with enzalutamide in prostate cancer after chemotherapy. N Engl J Med. https://doi.org/10.1056/nejmoa1207506

6. Smith MR, Saad F, Chowdhury S et al (2018) Apalutamide treatment and metastasis-free survival in prostate cancer. $\mathrm{N}$ Engl $\mathbf{J}$ Med. https://doi.org/10.1056/nejmoa1715546

7. Sternberg CN, Castellano D, Daugaard G et al (2014) Abiraterone acetate for patients with metastatic castration-resistant prostate cancer progressing after chemotherapy: final analysis of a multicentre, open-label, early-access protocol trial. Lancet Oncol. https://doi.org/10.1016/S1470-2045(14)70417-6

8. Heinlein CA, Chang C (2004) Androgen receptor in prostate cancer. Endocr Rev 105(34):12182-12187

9. Tan ME, Li J, Xu HE et al (2015) Androgen receptor: Structure, role in prostate cancer and drug discovery. Acta Pharmacol Sin 36(1):3-23

10. Weiner AB, Cohen JE, DeLancey JO et al (2020) Surgical versus medical castration for metastatic prostate cancer: use and overall survival in a National Cohort. J Urol. https://doi.org/10.1097/ju. 0000000000000684

11. Garje R, Chennamadhavuni A, Mott SL et al (2020) Utilization and outcomes of surgical castration in comparison to medical castration in metastatic prostate cancer. Clin Genitourin Cancer. https://doi.org/10.1016/j.clgc.2019.09.020

12. Karantanos T, Corn PG, Thompson TC (2013) Prostate cancer progression after androgen deprivation therapy: mechanisms of castrate resistance and novel therapeutic approaches. Oncogene 32(49):5501-5511

13. Pal SK, Patel J, He M et al (2018) Identification of mechanisms of resistance to treatment with abiraterone acetate or enzalutamide in patients with castration-resistant prostate cancer (CRPC). Cancer. https://doi.org/10.1002/cncr.31161

14. Bremmer F, Jarry H, Strauß A et al (2014) Increased expression of CYP17A1 indicates an effective targeting of the androgen receptor axis in castration resistant prostate cancer (CRPC). J Korean Phys Soc. https://doi.org/10.1186/2193-1801-3-574

15. Kluetz PG, Ning YM, Maher VE et al (2013) Abiraterone acetate in combination with prednisone for the treatment of patients with metastatic castration-resistant prostate cancer: US food and drug administration drug approval summary. Clin Cancer Res 19(24):6650-6656

16. Bedoya DJ, Mitsiades N (2014) Expert Review of Anticancer Therapy Abiraterone acetate, a first-in-class CYP17 inhibitor, establishes a new treatment paradigm in castration-resistant 
prostate cancer. Expert Rev Anticancer Ther. https://doi.org/10. 1586/era.11.196

17. Amm J, Aragon Ching JB (2013) The changing landscape in the treatment of metastatic castration-resistant prostate cancer. Ther Adv Med Oncol 5(1):25-40

18. Bryce A, Ryan CJ (2012) Development and clinical utility of abiraterone acetate as an androgen synthesis inhibitor. Clin Pharmacol Ther 91(1):101-108

19. McKay RR, Silver R, Bhak RH et al (2020) Treatment of metastatic castration resistant prostate cancer with radium-223: a retrospective study at a US tertiary oncology center. Prostate Cancer Prostatic Dis. https://doi.org/10.1038/s41391-020-00271-7

20. US Food and Drug Administration (2018) FDA approves abiraterone acetate in combination with prednisone for high-risk metastatic castration-sensitive prostate cancer. https://www.fda. gov/drugs/informationondrugs/approveddrugs/ucm596015.htm. Accessed 15 June 2020

21. Sipra QUAR, Bin RI, Asghar N et al (2020) Treatment of metastatic castration sensitive prostate cancer (mCSPC) by disease volume: A systematic review and a meta-analysis. J Clin Oncol. https://doi.org/10.1200/jco.2020.38.15_suppl.e17539

22. Fragni M, Galli D, Nardini M et al (2019) Abiraterone acetate exerts a cytotoxic effect in human prostate cancer cell lines. Naunyn Schmiedebergs Arch Pharmacol. https://doi.org/10.1007/ s00210-019-01622-5

23. Grossebrummel H, Peter T, Mandelkow R et al (2016) Cytochrome P450 17A1 inhibitor abiraterone attenuates cellular growth of prostate cancer cells independently from androgen receptor signaling by modulation of oncogenic and apoptotic pathways. Int J Oncol. https://doi.org/10.3892/ijo.2015.3274

24. Li WH, Qiu Y, Zhang HQ et al (2013) P2Y2 receptor promotes cell invasion and metastasis in prostate cancer cells. Br J Cancer. https://doi.org/10.1038/bjc.2013.484

25. Shabbir M, Ryten M, Thompson C et al (2008) Characterization of calcium-independent purinergic receptor-mediated apoptosis in hormone-refractory prostate cancer. BJU Int. https://doi.org/ 10.1111/j.1464-410X.2007.07293.x

26. Wei Q, Costanzi S, Liu QZ et al (2011) Activation of the P2Y1 receptor induces apoptosis and inhibits proliferation of prostate cancer cells. Biochem Pharmacol. https://doi.org/10.1016/j.bcp. 2011.05.013

27. Janssens R, Communi D, Pirotton S et al (1996) Cloning and tissue distribution of the human P2Y1 receptor. Biochem Biophys Res Commun. https://doi.org/10.1006/bbrc.1996.0640

28. Le HTT, Rimpilainen T, Konda Mani S et al (2019) Synthesis and preclinical validation of novel P2Y1 receptor ligands as a potent anti-prostate cancer agent. Sci Rep. https://doi.org/10.1038/ s41598-019-55194-8

29. Le HTT, Murugesan A, Ramesh T et al (2021) Molecular interaction of HIC, an agonist of P2Y1 receptor, and its role in prostate cancer apoptosis. Int J Biol Macromol 189:142-150. https://doi. org/10.1016/j.ijbiomac.2021.08.103

30. Le HTT, Murugesan A, Candeias NR et al (2021) Functional characterization of $\mathrm{HIC}$, a P2Y1 agonist, as a p53 stabilizer for prostate cancer cell death induction. Futur Med Che 13(21):1845-1864

31. Chou TC (2006) Theoretical basis, experimental design, and computerized simulation of synergism and antagonism in drug combination studies. Pharmacol Rev 58(3):621-681

32. Chou TC, Talalay P (1984) Quantitative analysis of dose-effect relationships: the combined effects of multiple drugs or enzyme inhibitors. Adv Enzyme Regul. https://doi.org/10.1016/00652571(84)90007-4

33. Chou TC (2018) The combination index $(\mathrm{CI}<1)$ as the definition of synergism and of synergy claims. Synergy 7:49-50

34. McQuin C, Goodman A, Chernyshev V et al (2018) Cell profiler 3.0: next-generation image processing for biology. PLoS Biol. https://doi.org/10.1371/journal.pbio.2005970

35. Brentnall M, Rodriguez-Menocal L, De Guevara RL et al (2013) Caspase-9, caspase-3 and caspase-7 have distinct roles during intrinsic apoptosis. BMC Cell Biol. https://doi.org/10.1186/ 1471-2121-14-32

36. Le Thu HT, Murugesan A, Candeias NR et al (2021) Functional characterization of HIC, a P2Y1 agonist, as a p53 stabilizer for prostate cancer cell death induction. Future Med Chem. https:// doi.org/10.4155/fmc-2021-0159

37. Redza-Dutordoir M, Averill-Bates DA (2016) Activation of apoptosis signalling pathways by reactive oxygen species. Biochim Biophys Acta Mol Cell Res 1863:2977-2992

38. Simon HU, Haj-Yehia A, Levi-Schaffer F (2000) Role of reactive oxygen species (ROS) in apoptosis induction. Apoptosis. https:// doi.org/10.1023/A:1009616228304

39. Fleury C, Mignotte B, Vayssière JL (2002) Mitochondrial reactive oxygen species in cell death signaling. Biochimie. https://doi.org/ 10.1016/S0300-9084(02)01369-X

40. Feher A, Ötvös K, Pasternak TP, Pettkó-Szandtner A (2008) The involvement of reactive oxygen species (ROS) in the cell cycle activation (G 0 -to-G 1 transition) of plant cells. Plant Signal Behav. https://doi.org/10.4161/psb.3.10.5908

41. Vermeulen K, Berneman ZN, Van Bockstaele DR (2003) Cell cycle and apoptosis. Cell Prolif 36(3):165-175

42. Elmore $S$ (2007) Apoptosis: a review of programmed cell death. Toxicol Pathol 35:495-516. https://doi.org/10.1080/0192623070 1320337

43. Martin T, Ye L, Sanders A, et al (2014) Cancer invasion and metastasis: molecular and cellular perspective. Metastatic Cancer Clin Biol Perspect

44. Ju A, Cho YC, Kim BR et al (2018) Anticancer effects of methanol extract of Myrmecodia platytyrea Becc leaves against human hepatocellular carcinoma cells via inhibition of ERK and STAT3 signaling pathways. Int J Oncol. https://doi.org/10.3892/ijo.2017. 4178

45. Bagnyukova T, Serebriiskii IG, Zhou Y et al (2010) Chemotherapy and signaling: how can targeted therapies supercharge cytotoxic agents? Cancer Biol Ther 10:839-853

46. Ozaki T, Nakagawara A (2011) Role of p53 in cell death and human cancers. Cancers (Basel) 3:994-1013

47. Lossi L, Castagna C, Merighi A (2018) Caspase-3 mediated cell death in the normal development of the mammalian cerebellum. Int J Mol Sci 19(12):3999

48. Zhang JH, Xu M (2000) DNA fragmentation in apoptosis. Cell Res 10:205-211

Publisher's Note Springer Nature remains neutral with regard to jurisdictional claims in published maps and institutional affiliations. 